Le devisement du monde. Edition critique publiée sous la direction de Philippe Ménard, Tome I, Départ des voyageurs et traversée de la Perse, Paris, Droz, Textes littéraires français, 2001, 286 p.

\title{
Denise Aigle
}

\section{OpenEdition}

\section{Journals}

Édition électronique

URL : http://journals.openedition.org/abstractairanica/34404

DOI : 10.4000/abstractairanica.34404

ISSN : 1961-960X

Éditeur :

CNRS (UMR 7528 Mondes iraniens et indiens), Éditions de l'IFRI

Édition imprimée

Date de publication : 15 mai 2003

ISSN : 0240-8910

\section{Référence électronique}

Denise Aigle, « Le devisement du monde. Edition critique publiée sous la direction de Philippe Ménard,

Tome I, Départ des voyageurs et traversée de la Perse, Paris, Droz, Textes littéraires français, 2001, 286 p. », Abstracta Iranica [En ligne], Volume 24 | 2003, document 114, mis en ligne le 05 janvier 2010 consulté le 25 septembre 2020. URL : http://journals.openedition.org/abstractairanica/34404 ; DOI : https://doi.org/10.4000/abstractairanica.34404

Ce document a été généré automatiquement le 25 septembre 2020.

Tous droits réservés 
Le devisement du monde. Edition critique publiée sous la direction de Philippe Ménard, Tome I, Départ des voyageurs et traversée de la Perse, Paris, Droz, Textes littéraires

\title{
français, 2001, 286 p.
}

\author{
Denise Aigle
}

1 Comme l'écrit justement Philippe Ménard, l'édition de cette œuvre importante de Marco Polo est une entreprise qui dépasse largement les forces d'un seul chercheur. Il a donc rassemblé autour de lui une équipe dont l'objectif est de publier, en plusieurs volumes, le Devisement du monde.

2 Le Devisement comporte trois grandes parties : un prologue (chap. 1 à 18), une deuxième partie divisée elle-même en deux sous-parties, le voyage vers la Chine (chap. 19 à 74) et la personne du grand Khan (chap. 75 à 156), puis une troisième partie qui débute au chap. 157 : «Ci commence le livre de l'Inde».

3 Le volume I, dont il est question ici, est consacré aux chapitres 1 à 42 , édités sous la responsabilité de Philippe Ménard assisté de M. Guéret-Laferté et de M.L. Chênerie. L'édition repose sur une étude de l'ensemble de la tradition manuscrite, en toutes langues. Les auteurs affirment ne pas prétendre «reconstruire » le texte original de Marco Polo car il est fort difficile de distinguer dans toutes les versions existantes ce qui est propre à l'auteur de ce qui serait une addition ultérieure. Grâce à une étude très fine de la tradition manuscrite, les auteurs ont regroupé les manuscrits par " familles » à partir de critères de choix reposant sur la langue : étude des graphies et des traits dialectaux (picardismes par exemple).

4 Le volume se compose d'une introduction substantielle (pp. 1-116), du texte en ancien français (pp. 117-169), suivi d'un apparat critique de notes (pp. 171-219) et des variantes 
(pp. 221-258). Figurent également dans ce volume un index des noms propres, des noms de lieux (pp. 259-264), un utile glossaire des termes en ancien français avec leur équivalent en français actuel, 6 illustrations tirées du manuscrit de la BNF et 3 cartes présentant l'itinéraire présumé du premier voyage des frères Polo, l'itinéraire présumé de Marco Polo en Perse, de Tabriz en Afghanistan, et les routes habituelles des caravanes et des navires entre l'Extrême-Orient et l'Occident.

On peut regretter cependant que, plutôt que la «bibliographie sélective » incluse dans l'introduction, les auteurs n'aient pas prévu une véritable bibliographie en fin de volume, regroupant également les références citées dans les notes.

Le Devisement du monde, rédigé à la fin du $13^{\mathrm{e}} \mathrm{s}$., est le premier récit de voyage écrit en français qui donne une vision d'ensemble de la Perse, de l'Asie centrale et de l'ExtrêmeOrient. En effet, avant Marco Polo, Jean de Plan Carpin et Guillaume de Rubrouck avaient décrit leur voyage au "pays des Tartares» en latin. Ces derniers étant, par ailleurs, des religieux, leurs préoccupations étaient fort différentes de celles de Marco Polo.

7 Nous donnons ici quelques éléments sur le contenu des chapitres consacrés à la Perse. Dans les chapitres 30 «Ci dit le .xxx. chapitre de la province de Persse» (pp. 150-152) et 31 «Ci dit le .xxxi. chapitre des .iii. roys qui retournoient» (pp. 152-153), Marco Polo évoque la Persie, grande province anciennement noble mais " gastee et destruite » par les «Tartares ». Il rapporte une version de la légende des trois Rois Mages qui seraient partis de Sarra (Saweh) et qui y seraient enterrés. Dans le chapitre 32, «Ce dit le .xxxii. chapitre des .viii. royaumes de Perse » (pp. 153-155), il donne le nom des royaumes de Perse : Casiun [Qazvīn], Cardistan [Kūrdistān], Lor [Luristān], Cielstan [Šūlistān], Istaint [Ișfahān], Serasy [Šīrāz], Sousara [Šabankāra] et Tunetain (?) qui est à «l'issue de la Persie ». Ses observations sur la vie économique recoupent celles des géographes: tissage de la soie, du coton, culture de l'orge, du blé, des fruits. Dans le même esprit, dans les chapitres 33 « Ci dit le .xxxiii. chapitre de la grant cité de Jasoy [Yazd]» et 34 "Ci dit le .xxxiiii. chapitre du royaume de Creman [Kirmān] » Marco Polo rapporte des légendes, recueillies oralement; il fait, également, la description des activités artisanales et des produits cultivés.

Bien que ce texte ne soit pas une source historique au sens propre du terme, nous pouvons y glaner quelques éléments factuels sur la vie des habitants des régions décrites. Par ailleurs, le Devisement apparaît comme le témoignage, le regard porté par un voyageur occidental sur la Perse à cette époque. Ce texte nous renseigne sur la représentation du monde, la culture et les préoccupations de son auteur.

9 La lecture du récit de Marco Polo sera utilement complétée par le livre de Michèle Guéret-Laferté, Sur les routes de l'empire mongol, Ordre et rhétorique des relations de voyage aux XIIIe et XIVe siècles, Paris, Honoré Champion, 1994, dans lequel elle fait le point sur cette littérature, particulière, du récit de voyage; par l'article d'Igor Rachewiltz, "Marco Polo went to China », Zentralasiatische Studien, 27 (1997), pp. 34-92, dans lequel l'auteur commente et discute la bibliographie concernant les voyages de Marco Polo. 
INDEX

Thèmes : 4.1. Histoire médiévale

\section{AUTEURS}

DENISE AIGLE

IFEAD - Damas 